International Journal of Distributed and Parallel Systems (IJDPS) Vol.4, No.1, January 2013

\title{
A STUDY ON PATH LOSS ANALYSIS FOR GSM MOBILE NETWORKS FOR URBAN, RURAL AND SUBURBAN REGIONS OF KARNATAKA STATE
}

\author{
N. Rakesh ${ }^{1}$, Dr.S.K.Srivatsa ${ }^{2}$ \\ ${ }^{1}$ Research Scholar, Centre for Research and Development, PRIST University, Tanjore, \\ Tamil Nadu, India. \\ sai_rakesh2005erediffmail.com \\ ${ }^{2}$ Senior Professor, St. Joseph College of Engineering, Chennai, Tamil Nadu, India. \\ profskserediffmail.com
}

\begin{abstract}
To establish any mobile network system, the basic task is to foresee the coverage of the proposed system in general. Many such different approaches have been developed, over the past, to predict coverage using what are known as propagation models. In this paper, measurement based path loss example and shadowing parameters are applied on path loss models. Here, the measurements are carried out in urban, rural and suburban areas considering non-line-of-sight terrains with low elevation antennas for the transceiver (Tx) and receiver (Rx)[5]. The impact of multipath are more emphasized in the rural context. This causes higher probability of RF signal errors. On the basis of observation and with the help of clutter, we can present models which give better understanding for urban, rural and suburban regions in Karnataka state at $940 \mathrm{MHz}$ GSM frequency[5],[26][13].
\end{abstract}

\section{KEYWORDS}

BS, Path Loss, Propagation, Model, GSM.

\section{INTRODUCTION}

Karnataka state is a tropical region, which comes as southern part of India. The Deccan plateau, which is not really flat, gradually rises towards the south west. The plateau is still surrounded with craters in the form of chain of mountains and isolated peaks. Here, rural areas are rich in green vegetation. Urban areas have moderate climatic atmosphere, with most of the localities in flat surface terrains and suburban is the combination of the both [5]. GSM (Global System for Mobile Communications) comes under wireless communication, which depends on the propagation of waves in the free space and providing transmission of data [13],[21]-[26]. It extends service by providing mobility for users, which fulfills the subscribers demand at any terrain covered by wireless network. When we consider the earlier historical legacy, the growth in mobile communications field has now become less. Here, the paramount factor was to serve for high quality and high capacity networks. Estimated coverage precisely has become very pivotal. So, in lieu of accomplishing far more accurate design, coverage of modem cellular networks and signal strength measurements will be considered as source of data, in order to provide reliable and efficient coverage locality. This paper focuses on the comparisons between theoretical and experimental analysis, at channel propagation path loss models at GSM frequency of $940 \mathrm{MHz}$, for various terrains in Karnataka state. Here, the clutters show the vegetation of the different areas for propagation of RF signals [1],[2],[3],[4],[5],[13],[22]-[29]. Figure 1.a. shows the framework of GSM technology. 
International Journal of Distributed and Parallel Systems (IJDPS) Vol.4, No.1, January 2013

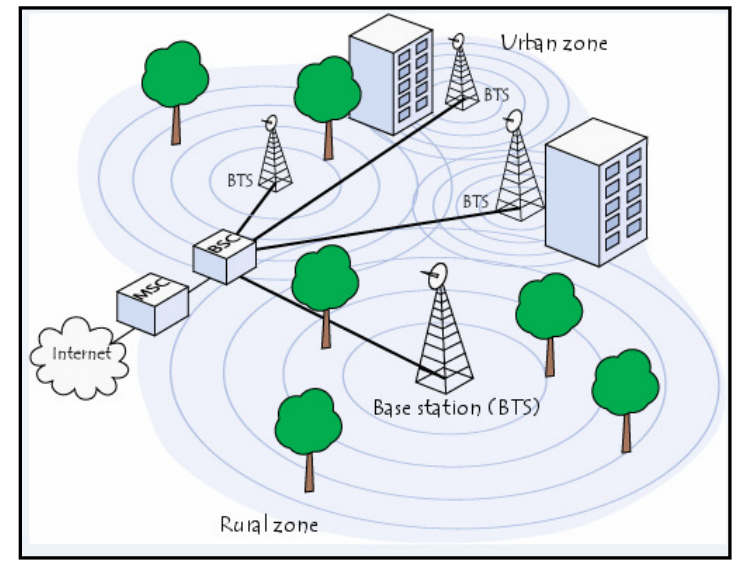

Figure 1.a. GSM framework

\section{SIGNIFICANCE OF PROPAGATION FORECAST:}

Planning is the key before implementing designs, and also setting up of wireless communication systems. Precise propagation characteristics of the situation should be known. Usually propagation provides two types of data, corresponding to the large-scale path loss and smallscale statistics pertaining to fading issue. Information regarding path-loss is very pivotal, for knowing the coverage of a base-station (BS) and in tuning it. The statistics provided by the small-scale parameters pertain only to local field variations. Also in turn this helps to improvise receiver (Rx) design structure and counter the multipath fading[5],[14],[15]-[34].

\section{VARIOUS TYPES PATH-LOSS PREDICTION MODELS}

\subsection{Empirical Model}

It is derived from in-depth field measurements. It is efficient and simple to use. The input data for the empirical models are generally qualitative, also not very correct, for instance like dense urban area, rural area and so on [5]-[16].

\subsection{Site-specific models}

It is based on numerical methods and the finite difference time-domain (FDTD) method. The input data can be very precise and detailed one [9].

\subsection{Theoretical models}

It is derived by physical hypothetical assumption, in addition to some moderate conditions. For instance, when we consider the over-rooftop, diffraction model is derived using physical optics, assuming constant heights and spacing of buildings [4].

\section{DIFFERENT TYPES OF PROPAGATION PATH-LOSS MODELS:}

\subsection{Cost Hata 231 model}

It is recommended for mathematical expression. To calculate the graphical data precisely, its usage has been put to test at $940 \mathrm{MHz}$ GSM frequency, to foresee the channel path-loss from source distance $d$ which is the transceiver to the destination receiver antenna upto $5 \mathrm{~km}$; transmitter antenna height of $60 \mathrm{~m}$ and receiver antenna height of $3 \mathrm{~m}$. To make a study of pathloss in the GSM frequency range of $940 \mathrm{MHz}$ in urban environment, this method is suggested.

$$
\mathrm{PL}=48.5+35.9 \log 10(\mathrm{f})-14.84 \log 10\left(\mathrm{~h}_{\mathrm{b}}\right)-\mathrm{ah}_{\mathrm{m}}+\left(45.8-6.58 \log 10\left(\mathrm{~h}_{\mathrm{b}}\right)\right) \log 10 \mathrm{~d}+\mathrm{cm}
$$


where: $\mathrm{d}=$ Distance between transmitter and receiver antenna $[\mathrm{km}]$

f: Frequency $[\mathrm{MHz}]$

$\mathrm{h}_{\mathrm{b}}$ : Transmitter antenna height $[\mathrm{m}]$

The parameter $\mathrm{cm}$ has different values for different environments like $3 \mathrm{~dB}$ for urban areas and the remaining parameter $\mathrm{ah}_{\mathrm{m}}$ is defined in urban areas as,

[5]-[19].

$$
\mathrm{ah}_{\mathrm{m}}=3.25\left(\log 10\left(11.80 \mathrm{~h}_{\mathrm{r}}\right)\right) 2-4.81, \quad \text { for } \mathrm{f}>940 \mathrm{MHz}
$$

\subsection{Free space model}

It emphasizes on how much strength of signal transmission between transceiver and receiver is lost.

To calculate the same, we use the following equation:

$$
\mathrm{PL}_{\mathrm{FSPL}}=32.48+20 \log 10(\mathrm{~d})+20 \log 10(\mathrm{f})
$$

where,

f: Frequency $[\mathrm{MHz}]$

$\mathrm{d}$ : Distance between transmitter and receiver $[\mathrm{m}]$

Power is usually expressed in decibels $(\mathrm{dBm})$

[5],[6]-[8].

\subsection{Ericsson model}

To predict the path loss, software is provided for network planning engineers developed by Ericsson company. So, it is called as Ericsson model. The path loss according to this model is given by the equation:

$$
\mathrm{PL}=\mathrm{a} 0+\mathrm{a} 1 \cdot \log 10(\mathrm{~d})+\mathrm{a} 2 \cdot \log 10\left(\mathrm{~h}_{\mathrm{b}}\right)+\mathrm{a} 3 \cdot \log 10\left(\mathrm{~h}_{\mathrm{b}}\right) \cdot \log 10(\mathrm{~d})-3 \cdot 3\left(\log 10\left(11.78 \mathrm{~h}_{\mathrm{r}}\right)^{2}\right)+\mathrm{g}(\mathrm{f})
$$

where $\mathrm{g}(\mathrm{f})$ is defined as:

$\left.g(f)=44.51 \log 10(f)-4.79(\log 10(f))^{2}\right)$

$--(5)$

and

$\mathrm{f}=$ Frequency $\quad[\mathrm{MHz}]$

$\mathrm{h}_{\mathrm{b}}=$ Transmission antenna height $[\mathrm{m}]$

$\mathrm{h}_{\mathrm{r}}=$ Receiver antenna height $[\mathrm{m}]$

$[5],[10],[11]-[25]$.

\subsection{Hata model}

It falls under empirical propagation models. It is well suited model for the Ultra High Frequency (UHF) band. Currently, this model is tested with $940 \mathrm{MHz}$ GSM frequency. Here, empirical calculation method is applied to predict the model at, frequency range $940 \mathrm{MHz}$. In this model, path loss is given by the following equation,

$$
P L=A_{f s}+A_{b m}-G_{b}-G_{r}
$$

where

$\mathrm{A}_{\mathrm{fs}}=$ Free space attenuation

$\mathrm{A}_{\mathrm{bm}}=$ Basic median path loss

$[\mathrm{dB}]$

$\mathrm{G}_{\mathrm{b}}=$ Transmitter antenna height gain factor and 
$\mathrm{G}_{\mathrm{r}}=$ Receiver antenna height gain factor

These factors can be divided and given by the equation:

$\mathrm{A}_{\mathrm{fs}}=93.6+20 \log 10+20 \log 10$ (f)

$\mathrm{A}_{\mathrm{bm}}=21.41+9.83 \log 10(\mathrm{~d})+8.782 \log 10(\mathrm{f})+9.58[\log 10(\mathrm{f})]^{2}$

$\mathrm{G}_{\mathrm{b}}=\log 10\left(\mathrm{~h}_{\mathrm{b}} / 200\right)\left\{14.865+6.1[\log 10(\mathrm{~d})]^{2}\right\}$

When dealing with gain for urban cities, the $G_{r}$ will be expressed in terms of the following:

$$
\mathrm{G}_{\mathrm{r}}=[42.58+13.7 \log 10(\mathrm{f})]\left[\log 10\left(\mathrm{~h}_{\mathrm{r}}\right)-0.586\right]
$$

For quite large urban areas,

$\mathrm{G}_{\mathrm{r}}=0.860 \mathrm{~h}_{\mathrm{r}}-1.960$

where,

$\mathrm{d}=$ Distance transmitter and receiver antenna in $[\mathrm{km}]$

$\mathrm{f}=$ frequency range in $[\mathrm{GHz}]$

$\mathrm{h}_{\mathrm{b}}=$ Transmitter antenna height in [m]

$\mathrm{h}_{\mathrm{r}}=$ Receiver antenna height in $[\mathrm{m}]$ and

[5],[19],[24],[25],[28]-[35].

\subsection{SUI model}

This model inherits Hata model's frequency. Hence it is tested with GSM frequency of 940MHz. Little bit of correction in parameters, can be extended up to $3 \mathrm{GHz}$ band frequency. In this model, the BS antenna height can be varied from $10 \mathrm{~m}$ to $80 \mathrm{~m}$ and at receiver end, the height can vary between $2 \mathrm{~m}$ to $20 \mathrm{~m}$.SUI model comes out with three different types of terrain like terrain A dense urban locality, terrain $\mathrm{B}$ has hilly regions and terrain $\mathrm{C}$ for rural with moderate vegetation. Here, we concentrate on urban path loss with different ranges of receiver antenna height. The general path loss expression of the SUI model is presented as :

$$
\mathrm{PL}=\mathrm{A}+1 \mathrm{Oy} \log 10(\mathrm{~d} / \mathrm{d} 0)+\mathrm{X}_{\mathrm{f}}+\mathrm{X}_{\mathrm{h}}+\mathrm{s} \text { for } \mathrm{d}>\mathrm{d} 0
$$

where the parameters are as follows,

$\mathrm{d}=$ Distance between BS and receiving antenna $\quad[\mathrm{m}]$

$\mathrm{d} 0=100 \quad[\mathrm{~m}]$

$\lambda=$ Wave length $[\mathrm{m}]$

$\mathrm{X}_{\mathrm{f}}=$ Correction for frequency $940[\mathrm{MHz}]$

$\mathrm{X}_{\mathrm{h}}=$ Correction for receiving antenna height $\quad[\mathrm{m}]$

$s=$ Correction for shadowing

and $\mathrm{y}=$ Path loss exponent

By statistical method, the random variables are taken as the path loss exponent $y$ and the weak fading standard $\mathrm{s}$ is derived. The parameter $\mathrm{A}$ is defined as,

$$
\mathrm{A}=20 \log 10\left(\frac{4 \pi \mathrm{d}_{0}}{\lambda}\right)
$$

and the path loss exponent $y$ is given as follows, 
International Journal of Distributed and Parallel Systems (IJDPS) Vol.4, No.1, January 2013

$$
\mathrm{Y}_{\mathrm{y}}=\mathrm{a}-\mathrm{bh} \mathrm{b}+\left(\mathrm{c} / \mathrm{h}_{\mathrm{b}}\right)
$$

Here, the parameter $h_{b}$ is the base station antenna height. This is between $15 \mathrm{~m}$ and $90 \mathrm{~m}$ range. The constants $\mathrm{a}, \mathrm{b}$, and $\mathrm{c}$ depend upon the types of terrain, here our study, urban area. The value of parameter $\gamma$ propagation in an urban area, $6<\gamma<9$ for urban NLOS environment. The frequency correction factor $\mathrm{X}_{\mathrm{f}}$ and the correction for antenna receiver height

$\mathrm{X}_{\mathrm{h}}$ for the model are expressed as follows,

$\mathrm{X}_{\mathrm{f}}=6.2 \log 10(\mathrm{f} / 2000)$

$\mathrm{X}_{\mathrm{h}}=-10.9 \log 10\left(\mathrm{~h}_{\mathrm{r}} / 2000\right)$

$[5],[12],[15],[16],[17]-[36]$.

\section{METHODOLOGY USED FOR MEASUREMENT}

\subsection{Configuration of measurement}

Here, the parameter consisted of constant transmitter and a receiver mounted to a car. A dipole antenna of omnidirectional quarter-wave with $4 \mathrm{dBi}$ was installed on a tripod and connection is established to the signal transmitter with a 12 meter feeder cable. The continuous narrowband wave signal with GSM frequency of $940 \mathrm{MHz}$ was input given to the Tx antenna with $30 \mathrm{dBm}$ power capacity. The spectrum analyzer inside the car gives details of the timing intervals for every one second. Figure 4.1.a. shows the framework of the above concept [9],[10],[11],[21],[22]-[24].

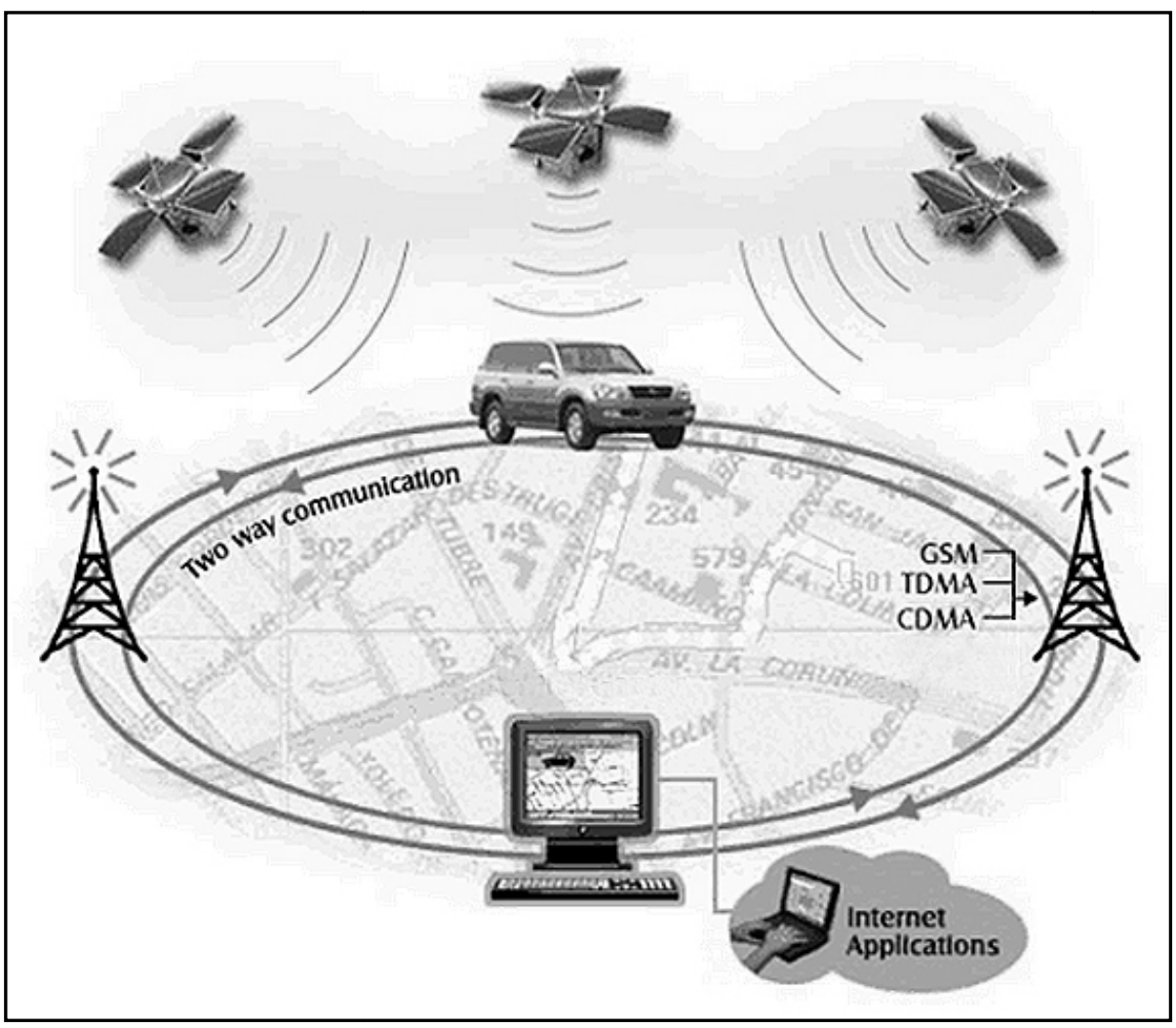

Figure 4.1.a. Measurement framework 


\subsection{Environmental measurement}

With GSM frequency of $940 \mathrm{MHz}$ RF signal, measurement were performed during July 2012 and the measurement campaign consisted of three slightly various propagation environments in MG Road,Bangalore,Karnataka,India;Channapatna, Karnataka,India;Kannaswadi, Karnataka, India. The field measurement survey was performed in Kannaswadi district reflecting a typical suburban region. The second measurement survey was performed in Bangalore district reflecting a typical urban region and the third measurement survey was performed in Channapatna district reflecting a typical rural region.

Typical urban region comprises of blocks of densely constructed buildings. In general, an average building height is more than 20 meters and buildings may have ten to fifteen floors. In conjunction, the region is surrounded by parks and open parking areas. Typically $25 \%$ of the area is filled with buildings built of concrete blocks. In rural region with thick vegetation of highly raised trees, some sequence of houses built with huts; and some part of the place with concreted buildings. Around $45 \%$ of the area filled with more huts, in contrast with suburban, which is combination of both counterparts [21],[26],[27],[30],[31].

\section{AERIAL VIEW OF THE CLUTTER SHOWING VARIOUS TERRAINS}

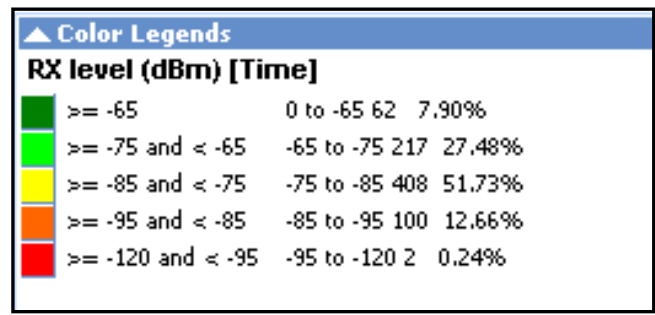

6. Table gives legends of different variations

Figure 6.a. shows the clutter of propagation signal in urban terrain of MG Road.

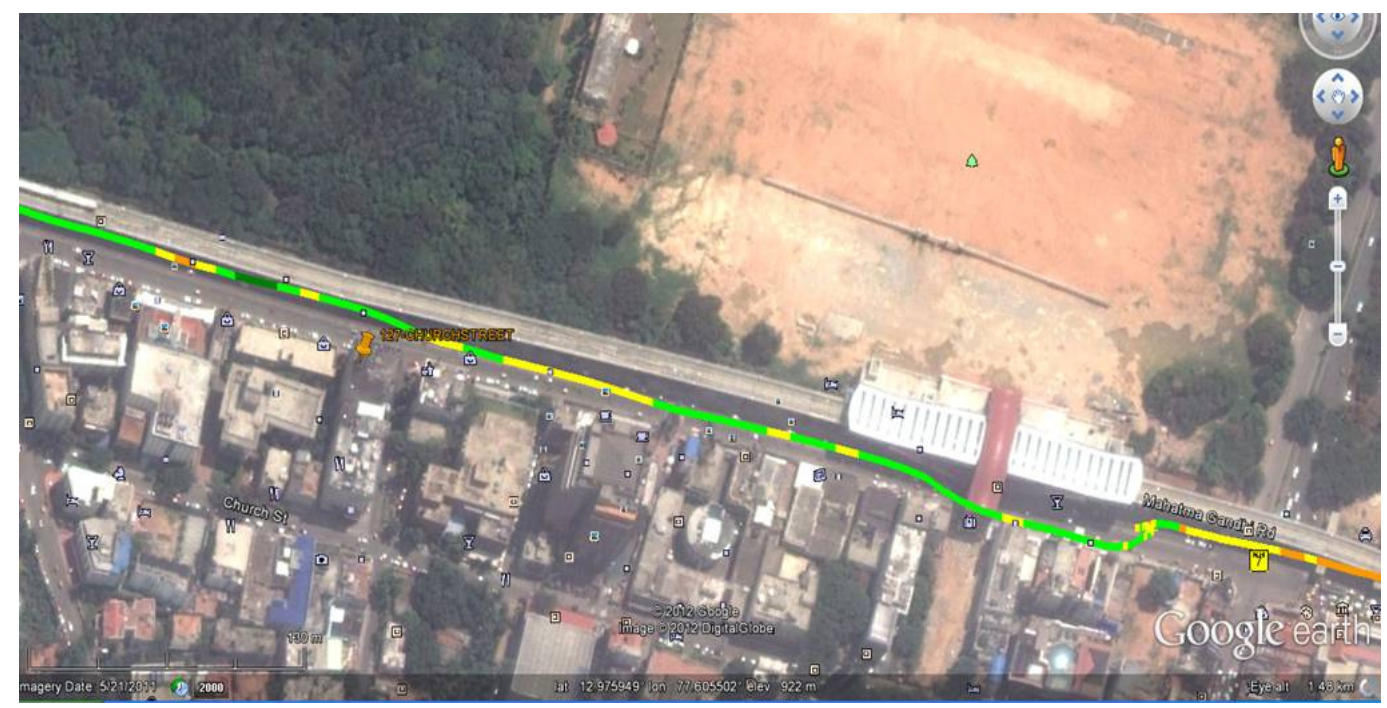

Figure 6.a. MG Road, Bangalore, Karnataka, India

Figure 6.b. shows the clutter of propagation signal in rural terrain of Channapatna. 
International Journal of Distributed and Parallel Systems (IJDPS) Vol.4, No.1, January 2013

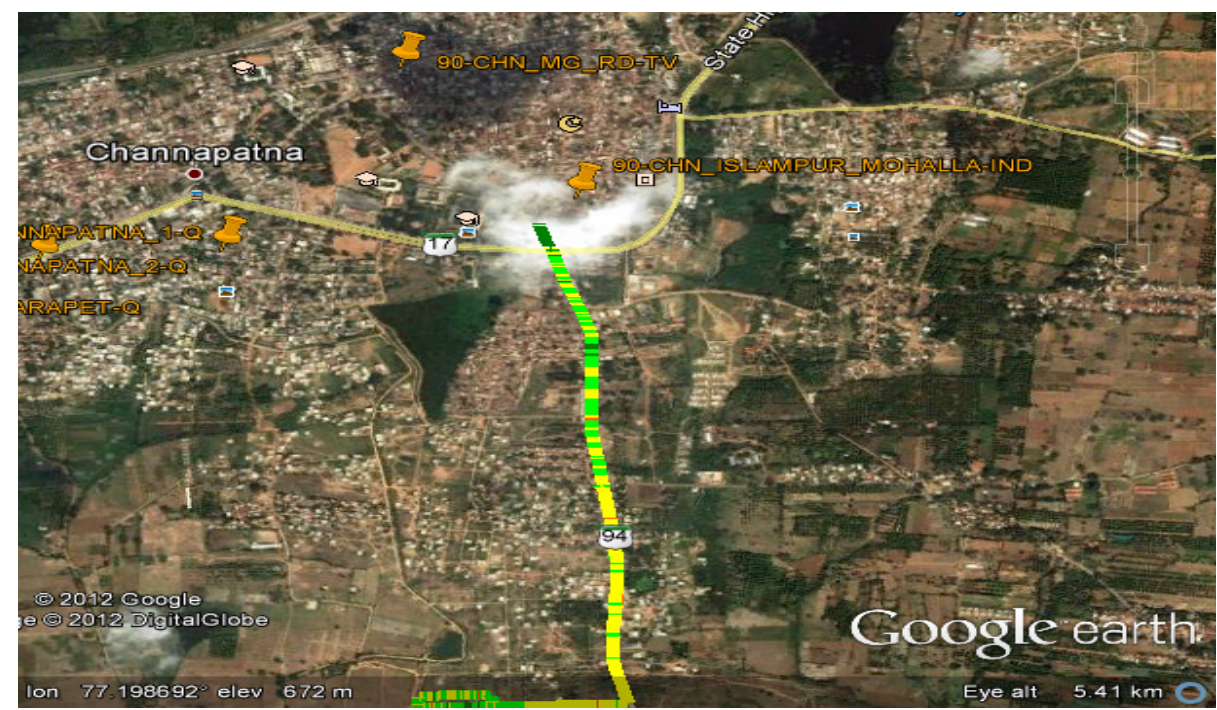

Figure 6.b. Channapatna, Karnataka, India

Figure 6.c. shows the clutter of propagation signal in suburban terrain of Kannaswadi.

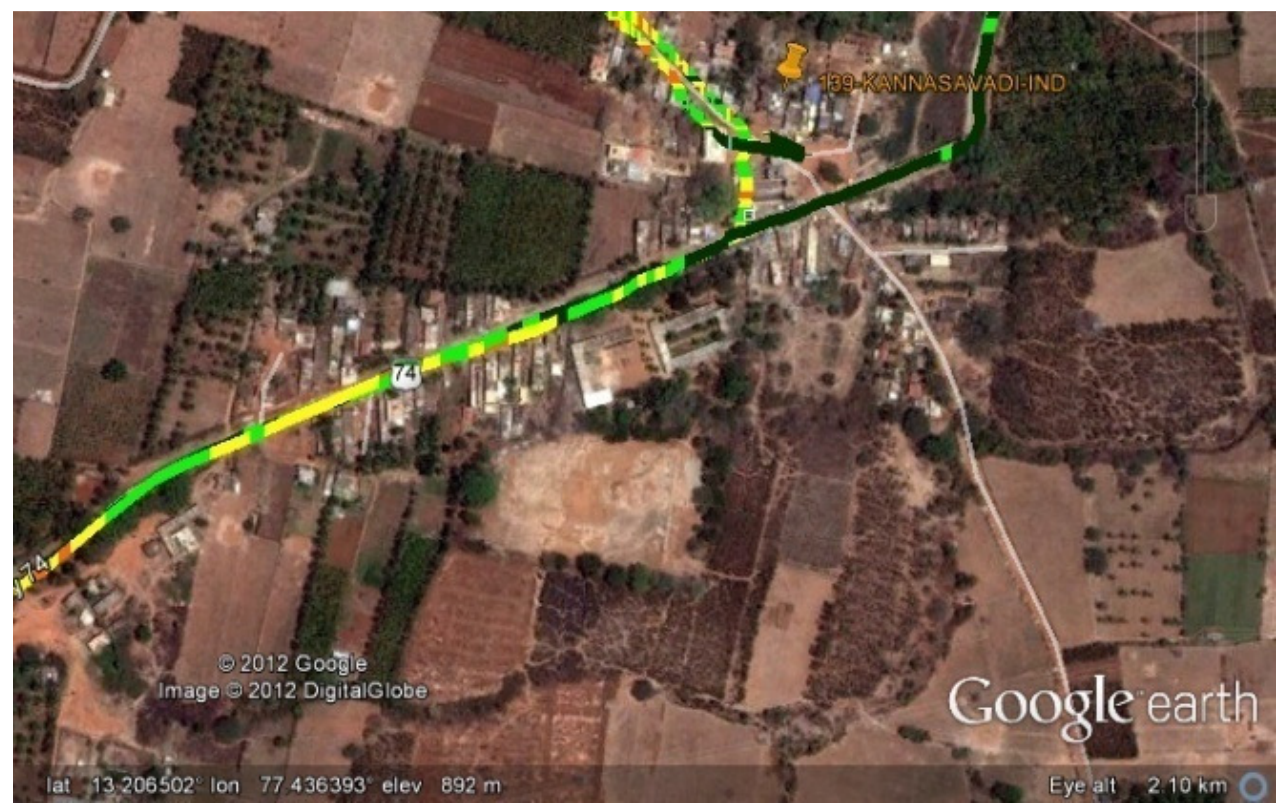

Figure 6.c. Kannaswadi, Karnataka, India

\section{EQUIPMENT AND MEASUREMENT DETAILS DEPLOYED}

To measure, we applied a drive test to measure in the location for which a path loss model is to be designed. Table 7.a. shows the equipment and data used for field measurement in urban area as follows. 
International Journal of Distributed and Parallel Systems (IJDPS) Vol.4, No.1, January 2013

Table 7.a. Measurement details for path loss at MG Road

\begin{tabular}{|l|l|l|l|}
\hline Antenna & \multicolumn{2}{|l|}{ Andrews } \\
\hline Model & \multicolumn{2}{|l|}{$65 / 6 \mathrm{deg}$ tilt } \\
\hline Gain & \multicolumn{2}{|l|}{$17 \mathrm{dbi}$} \\
\hline Mobile used & \multicolumn{2}{|l|}{ C5/antenna $7 \mathrm{dbi}$} & \multicolumn{2}{l|}{} \\
\hline Distance in km & Rx level in dBm & Tx power in dBM & Attenuation in dB \\
\hline 280 & -65 & 43 & 22 \\
\hline 400 & -75 & 43 & 32 \\
\hline 500 & -85 & 43 & 42 \\
\hline 800 & -95 & 43 & 52 \\
\hline
\end{tabular}

Table 7.b. shows the equipment and data used for field measurement in rural area as follows.

Table 7.b. Measurement details for path loss at Channapatna

\begin{tabular}{|l|l|l|l|}
\hline Antenna & \multicolumn{2}{|l|}{ Andrews } \\
\hline Model & $65 / 6 \mathrm{deg}$ tilt & \multicolumn{2}{|l|}{} \\
\hline Gain & \multicolumn{2}{|l|}{$17 \mathrm{dbi}$} & \multicolumn{2}{|l|}{} \\
\hline Mobile used & C5/antenna $7 \mathrm{dbi}$ & Attenuation in dB \\
\hline Distance in $\mathbf{~ k m}$ & Rx level in $\mathbf{~ d B m}$ & Tx power in dBM & 22 \\
\hline 150 & -65 & 43 & 22 \\
\hline 190 & -65 & 43 & 22 \\
\hline 200 & -65 & 43 & 32 \\
\hline 500 & -65 to -75 & 43 & 42 \\
\hline 1000 & -75 to -85 & 43 & \\
\hline
\end{tabular}

Table 7.c. shows the equipment and data used for field measurement in suburban area.

Table 7.c. Measurement details for path loss at Kannaswadi

\begin{tabular}{|l|l|l|l|}
\hline Antenna & Andrews \\
\hline Model & $65 / 6 \mathrm{deg}$ tilt & \multicolumn{2}{|l|}{} \\
\hline Gain & $17 \mathrm{dbi}$ & \multicolumn{2}{|l|}{} \\
\hline Mobile used & \multicolumn{2}{|l|}{ C5/antenna $7 \mathrm{dbi}$} & \multicolumn{2}{l|}{} \\
\hline Distance in $\mathbf{k m}$ & $\mathbf{R x}$ level in $\mathbf{d B m}$ & Tx power in dBM & Attenuation in dB \\
\hline 100 & -65 & 43 & 22 \\
\hline 190 & -65 & 43 & 22 \\
\hline 200 & -65 & 43 & 22 \\
\hline 800 & -65 to -75 & 43 & 32 \\
\hline 1800 & -75 to -85 & 43 & 42 \\
\hline
\end{tabular}


International Journal of Distributed and Parallel Systems (IJDPS) Vol.4, No.1, January 2013

\section{SiMULATED RESULTS OF VARIOUS TERRAINS}

The simulated output in Figure 8.a. generated shows the various model path losses in urban areas.

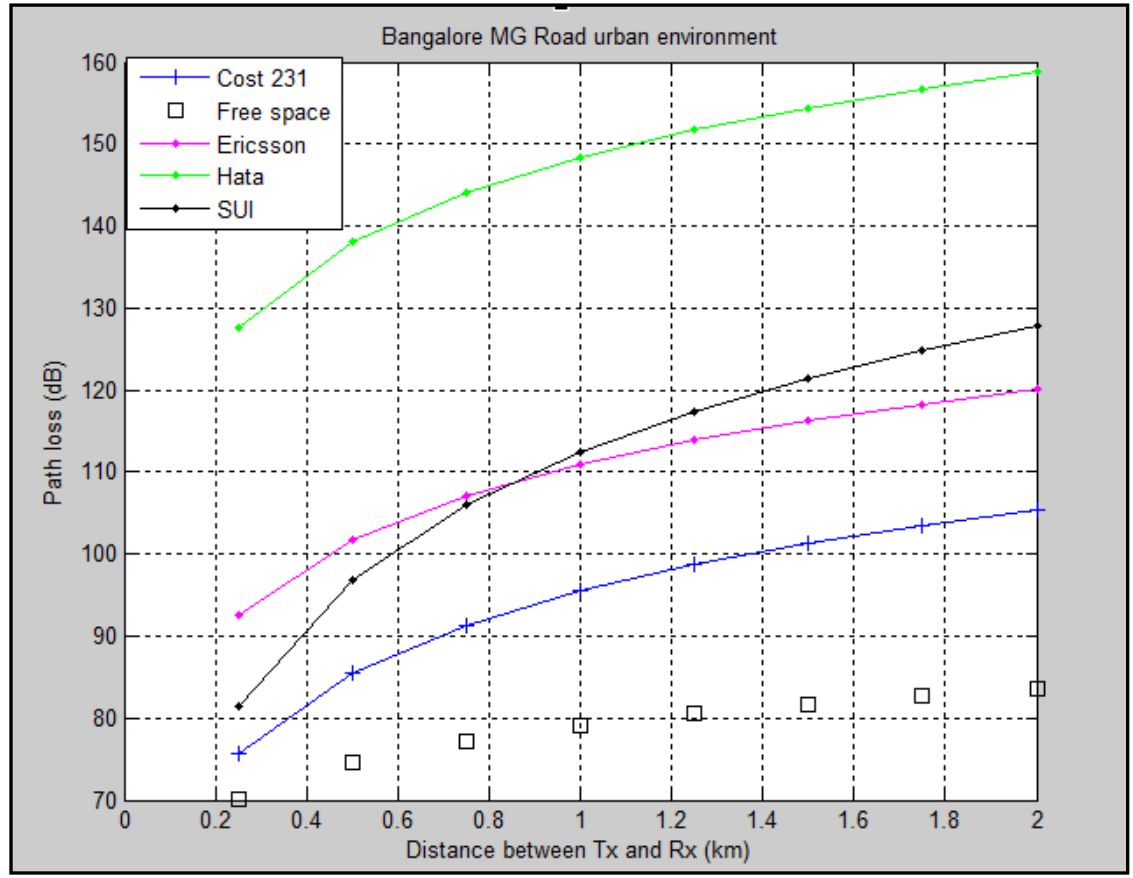

Figure 8.a. Path loss at MG road urban at $940 \mathrm{MHz}$ GSM frequency

The simulated output in Figure 8.b. generated shows the various model path losses in rural areas.

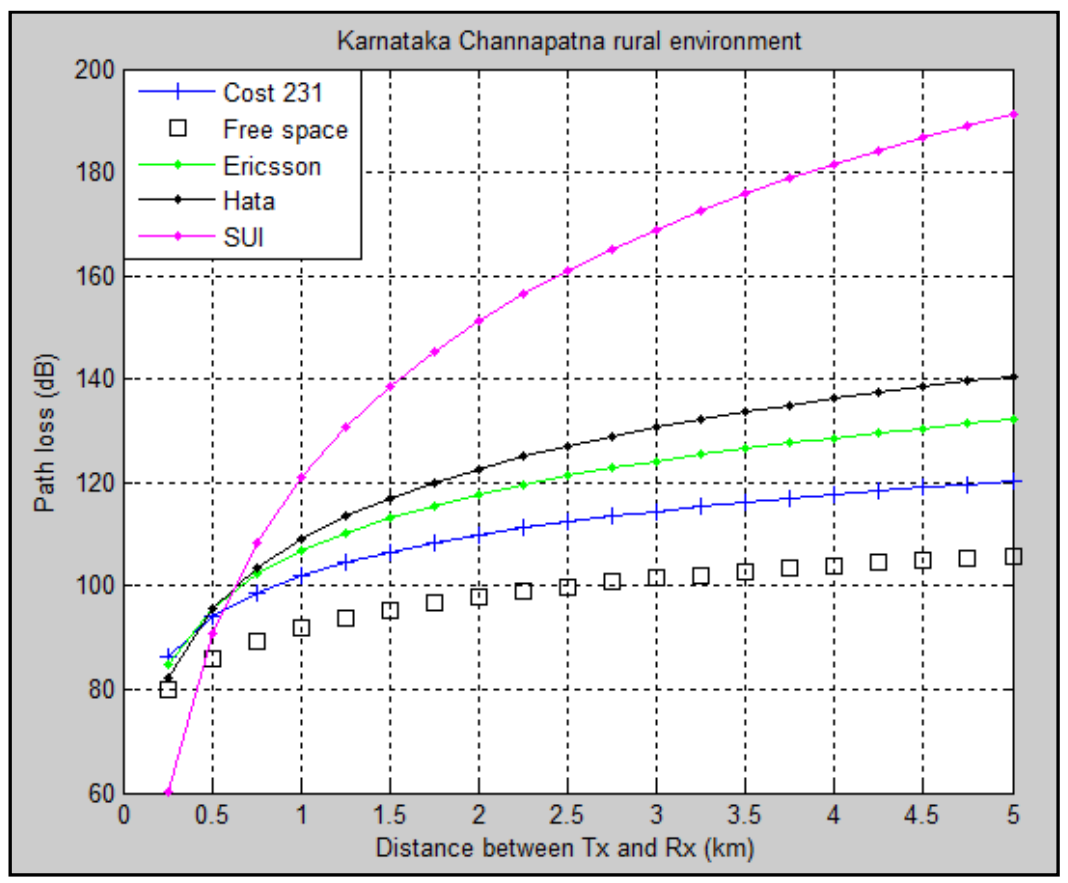

Figure 8.b. Path loss at Channapatna rural at $940 \mathrm{MHz}$ GSM frequency 
International Journal of Distributed and Parallel Systems (IJDPS) Vol.4, No.1, January 2013

The simulated output in Figure 8.c. generated shows the various model path losses in suburban areas.

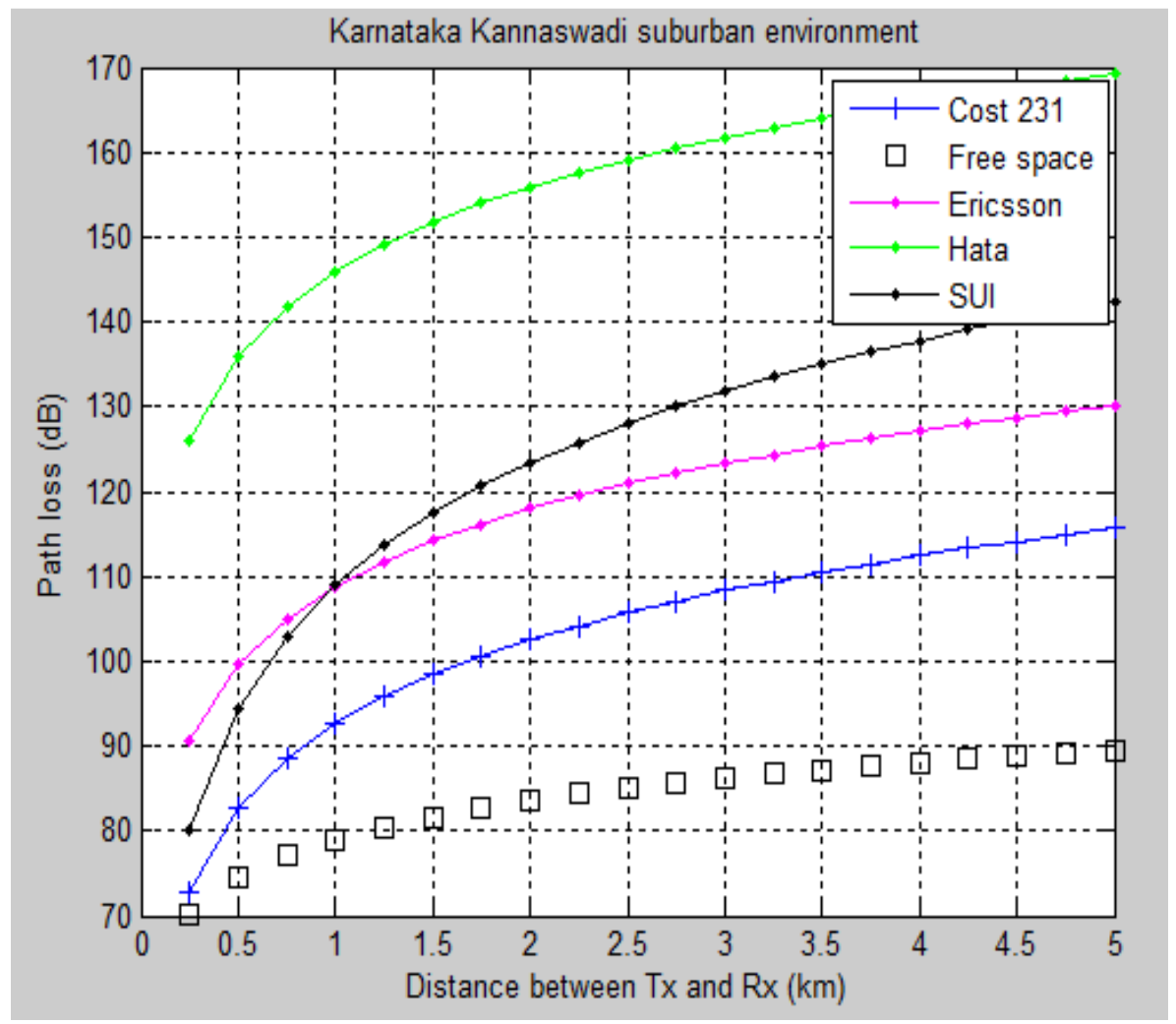

Figure 8.c. . Path loss at Kannaswadi suburban at 940 MHz GSM frequency

\section{ANALYSIS OF SIMULATED RESULTS OF VARIOUS TERRAINS}

The analysis in Figure 9.a. shows the transceiver Tx, receiver Rx and path loss in urban area of MG road.

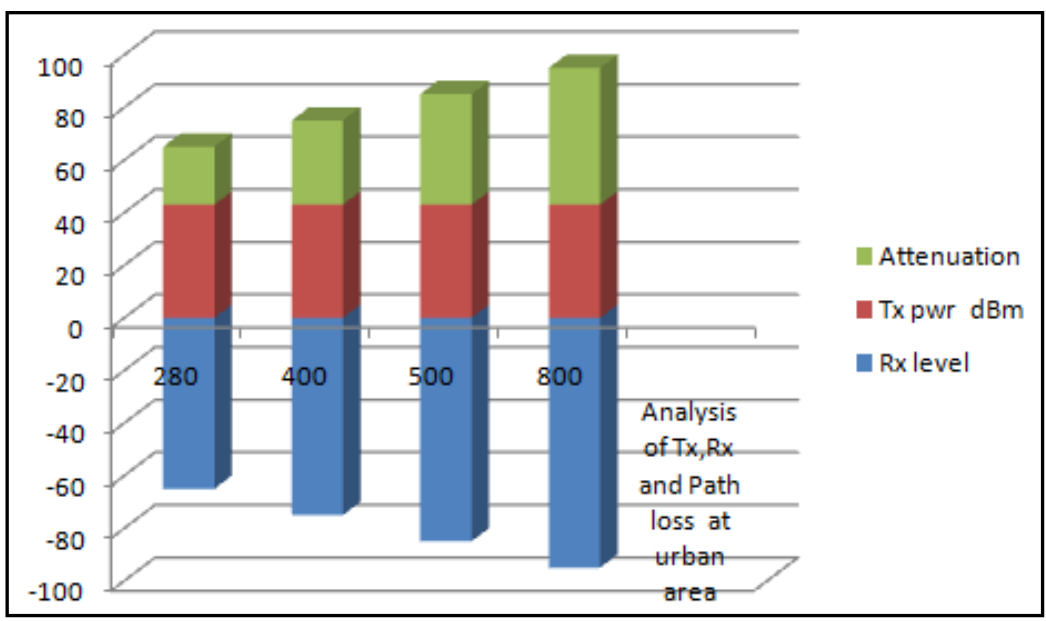

Figure 9.a Analysis of path loss at urban area 
International Journal of Distributed and Parallel Systems (IJDPS) Vol.4, No.1, January 2013

The analysis in Figure 9.b. shows the transceiver Tx, receiver Rx and path losses in rural area of Channapatna.

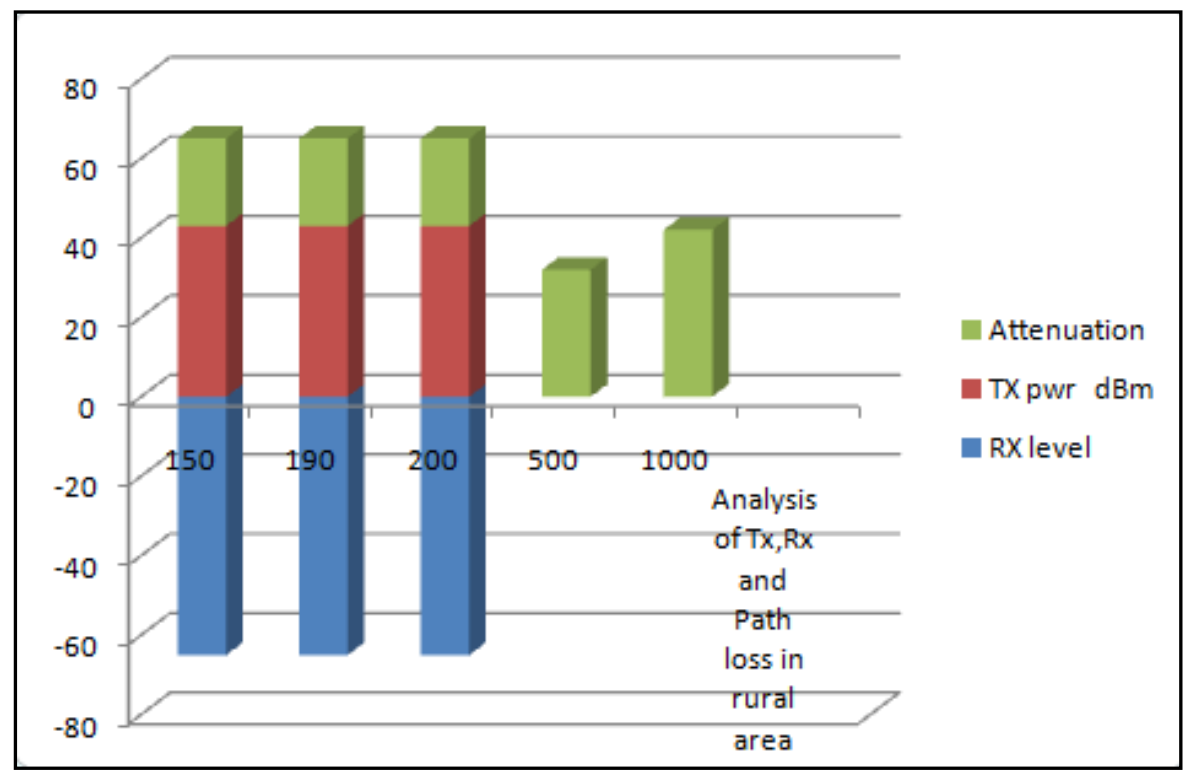

Figure 9.b. Analysis of path loss at rural area

The analysis in Figure 9.c. shows the transceiver Tx, receiver Rx and path loss in suburban area Kannaswadi.

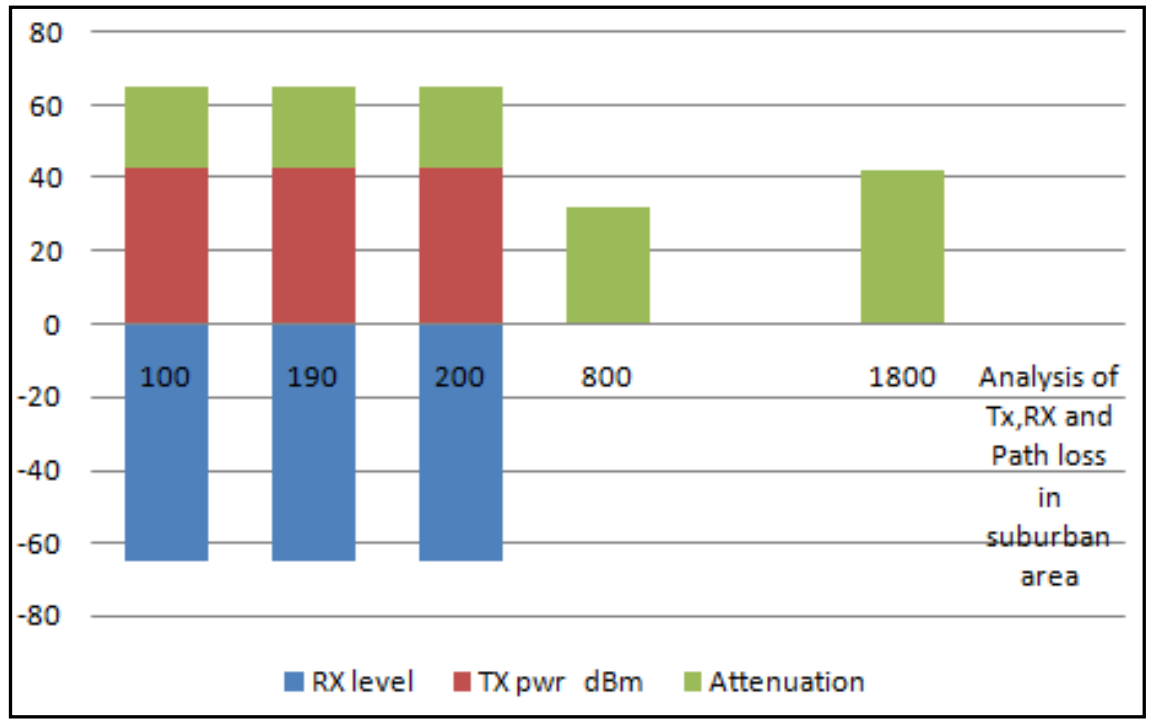

Figure 9.c. Analysis of path loss at suburban area 
International Journal of Distributed and Parallel Systems (IJDPS) Vol.4, No.1, January 2013

\section{Conclusions}

This work focuses on the path losses of various propagation models. For this, we have chosen three different terrains of Karnataka state like urban (MG Road), rural (Channapatna) and suburban (Kannaswadi). Here, we used drive test for achieving the same. With the help of spectrum analyzer and digital capture map tool, we were able to measure the path loss of various terrain regions and clutter of the same. To the measure the path loss between Tx and Rx, the RF range used was $940 \mathrm{MHz}$ GSM frequency. Free space model path loss is less compared to other with $85 \mathrm{~dB}$ in urban, $102 \mathrm{~dB}$ in rural and $89 \mathrm{~dB}$ in suburban. Hata model is at larger scale with $158 \mathrm{~dB}$ in urban area, $139 \mathrm{~dB}$ in rural area and $142 \mathrm{~dB}$ in suburban area. The SUI model is maximum in scale in case of rural environment. Further, the work is focused on to test with Wimax frequency of these terrains.

\section{ACKNOWLEDGMENT}

Authors would like to thank Mr.Srinivasan .A, NWS-RF Planning of IDEA cellular Ltd for providing the measurement equipment and guiding us to implement the concept successfully.

\section{REFERENCES}

[1] N.Rakesh and Dr.S.K. Srivatsa,'VoIP: An Overview and Security Aspects”, International Journal of Computational Intelligence and Information Security, Vol. 1 No. 9, November 2010,pp-66-69.

[2] N.Rakesh and Dr.S.K. Srivatsa,'Imparting Tutorials using online E-Commerce Application and Virtualization concept of Standalone PC Environment", Journal of Emerging Trends in Computing and Information Sciences, Vol. 2, No. 9, September 2011, pp-427 - 439.

[3] N.Rakesh and Dr.S.K.Srivatsa," A Study on Diverse Communication Protocols", International Journal of Computational Intelligence and Information Security, August 2011 Vol. 2, pp - 143-153.

[4] N.Rakesh and Dr.S.K.Srivatsa,” A Comprehensive investigation on SIP Protocol”, CiiT International Journal of Networking and Communication Engineering, Vol 3, No.9, July 2011, pp - 593-597.

[5] N. Rakesh and Dr.S.K. Srivatsa ," An Investigation on Propagation Path Loss in Urban Environments for Various Models at Transmitter Antenna Height of $50 \mathrm{~m}$ and Receiver Antenna Heights of 10 $\mathrm{m}, 15 \mathrm{~m}$ and $20 \mathrm{~m}$ respective"' International Journal of Research and Reviews in Computer Science “, Vol. 3, No. 4, pp. 1761-1767, August 2012.

[6] S. R. Saunders M. Hata, Empirical Formula for Propagation Loss in Land Mobile Radio Services, IEEETransactions on Vehicular Technology, Vol. VT 29 August 1980, pp. 317-325.

[7] Z. Nadir, N. Elfadhil, and F. Touati, Pathloss determination using Okumura-Hata model and spline interpolation for missing data for Oman World Congress on Engineering, IAENG-WCE-2008, Imperial College, London, United Kingdom, 2-4 July,2008, pp.422-425.

[8] M. Hata, "Empirical formula for propagation loss in land mobile radio services," IEEE Trans. Veh. Technol., vol. VT-29, pp. 317-325, Aug. 1980.

[9] S. Y. Seidel and T. S. Rappaport, "Site-specific propagation prediction for wireless in-building personal communication system design," IEEETrans. Veh. Technol., vol. 43, pp. 879-891, Nov. 1994.

[10] P. E. Morgensen, P. Eggers, C. Jensen and J. B. Andersen , "Urban Area Radio Propagation Measurements at 955 and 1845 MHz for Small and Micro Cells”, IEEE GLOBECOM '91, 1991.

[11] K. L. Blackard, M. J. Feuerstein, T. S. Rappaport, S. Y. Seidel S and H. H. Xia, "Path loss and delay spread models as functions of antenna height for microcellular system design", IEEE 42nd Vehicular Technology Conference, 1992.

[12] Sharma K, and Singh K., "Comparative Analysis of Propagation Path loss Models with Field Measured Data," International Journal of Engineering Science and Technology, Vol. 2, pp. 20082010, 2010. 
International Journal of Distributed and Parallel Systems (IJDPS) Vol.4, No.1, January 2013

[13] Gordon L. Stüber, (2002). Principles of Mobile Communication. USA:Kluwer Academic Publishers.

[14] Faruque, Saleh, (1996) "Propagation Prediction Based on Environmental Classification and Fuzzy Logic Approximation”, Proc.IEEE ICC $\square$ 96, pp 272-276.

[15]Wu, J. and Yuan, D., (1998) "Propagation Measurements and Modeling in Jinan City", IEEE International Symposium on Personal,Indoor and Mobile Radio Communications, Boston, MA, USA, Vol. 3,pp. 1157-1159.

[16] Azubogu, A.C.O et al. (2010) "Empirical-Statistical Propagation Pathloss Model for Suburban environment of Nigeria at $800 \mathrm{MHz}$ band", The IUP Journal of Science and Technology, India,pp-45-54.

[17] Moinuddin A .A. and Singh S, "Accurate Path Loss Prediction in Wireless Environment", Insttitution of Engineers (India), Vol 88,July 2007, pp. 09 - 13.

[18] Iskander M. and Yun Z., "Propagation Prediction Models for Wireless Communication Systems", IEEE Trans on microwave theory and Techniques, Vol. 50, No. 3, March 2002,pp-662-673.

[19] Nadir Z., Elfadhil, N. and Touati, F., (2008) "Pathloss Determination Using Okumura-Hata Model and Spline Interpolation for Missing Data for Oman Proceedings of the World Congress on Engineering" Vol I WCE 2008, July 2008, London, U.K,pp-2-4.

Well known model,
[Online].available:http://en.wikipedia.org/wiki/Radio_propagation_model [Accessed: April 11, 2009].

[21] Shalangwa, D. A. and Singh, K. S. (2010). Measurement and Modeling of path loss for GSM 900 in Sub Urban Environment over irregular terrain. Journal Computer Science and Network Security. 10(8): pp-268 - 274 .

[22] Yu - Huei, T. Wen - Shyang, H. and Ce - Kuen, S. (2009), "The influence of propagation in a live GSM network", Journal of electrical engineering.7 (1) pp $1-7$.

[23] Josiane, C. R., Simone, G. C. F., Herminio, S. G and Gervasio P. S. C. (2009). "Path loss model for densely Arboreous Citie in Amazon region": pp-1- 3.

[24] J. G. Andrews, A. Ghosh, and R. Muhamed. Fundamentals of WiMAX Understanding Broadband Wireless Networking. Prentice Hall.edition-2007.

[25] V. Erceg, L. J. Greenstein, S. Y. Tjandra, S. R. Parkoff, A. Gupta, B. Kulic, A.A. Julius and R. Bianchi, "An Empirically Based Path Loss Model for Wireless Channels in Suburban Environments", IEEE Journal on Selected Areas in Communications, Vol. 17, pp. 1205-1211, July 1999.

[26]Weather.uk.msn.com/region.aspx?wealocations=Karnataka

[27] Adebayo, A. A. (2004). "Mubi region a Geographical synthesis", 1st edition Paraclete Publishers Ltd, Nigeria. pp. $23-27$

[28] Y Okumura, "Field Strength and Its Variability In UHF And VHF Land Mobile Radio Service" ,Review Of Electrical Communication Laboratory, 1968 P16.

[29] W.C.Y.Lee, "Mobile Communication Design Fundamentals", (2nd Ed), John Wilely\&Sons, New York, 1993.

[30] V. Armoogum, K.M.S. Soyjaudah, N. Mohamudally, and T. Fogarty "Path Loss Analysis between the north and the south of Mauritius with some Existing Models for Digital Television Broadcasting for Summer Season at UHF Bands", Proceedings of the 8th IEEE AFRICON 2007 -ISBN 0-7803-8606-X.X.

[31] A. Arrinda, M. Ma Velez, P. Angueira, D. de la Vega, and J. L. Ordiales, "Local-Area Field Strength Variation Measurements Of The Digital Terrestrial Television Signal (COFDM 8k) In Suburban Environments”,IEEE Transactions On Broadcasting, Vol. 45, No. 4, pp. 386-391,(1999).

[32] J.D. Parsons and M.F. Ibrahim, "Signal strength prediction in built-up areas-Part 2: Signal variability”, IEE Proc., Vol. 130, No. 5, 1983, pp.385-391. 
International Journal of Distributed and Parallel Systems (IJDPS) Vol.4, No.1, January 2013

[33] F. Ikegami, S. Yoshida, T. Takeuchi, and M. Umehira, "Propagation factors controlling mean field strength on urban streets", IEEE Trans.Ant. Prop., Vol. 32 (no issue number), 1984, pp. 822-829.

[34] J. Walfisch and H. L. Bertoni, "A Theoretical Model of UHF Propagation in Urban Environments", IEEE Transactions On Antennas And Propagation, Vol. 36, No. 12, pp. 1788-1796, 1988.

[35] C. Perez-Vega and J.M. Zamanillo, "Path Loss Model for Broadcasting Applications and Outdoor Communication Systems in the VHF and UHF Bands", IEEE Transactions On Broadcasting, Vol. 48, No. 2, pp. 91-96,2002.

\section{Authors}

Mr.N.Rakesh is a PhD Student in Computer Science and Engineering at PRIST University,Thanjavur,Tamilnadu.Currently he is working as Assistant Professor in Department of Information Science and Engineering at KNS Institute of Technology, Bangalore. He received the B.E in Information Science and Engineering degree from Visvesvaraya Technological University Belgaum, Karnataka and M.Tech in Computer Science and Engineering degree from Dr.M.G.R.University, Chennai in 2005 and 2007 respectively. Subsequently completed M.B.A in Systems from Alagappa University, Karaikudi, Tamilnadu

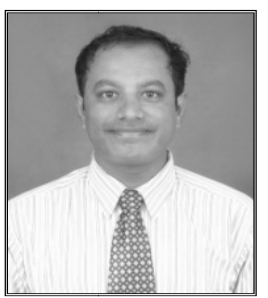
and M.Sc in Computer Science from Alagappa University, Karaikudi, Tamilnadu in 2009 and 2011 respectively. He is having 7 years of experience in academics and published papers in international journals, also is a member of CSI. His current research activities pertain to VOIP, ATM, Frame Relays, Network Security, Information Security, Wireless sensor Network and topics related to Networks.

Dr.S.K.Srivatsa received the B.E from Jadavpur University in 1968. He received the M.E and PhD degree from IISc Bangalore in 1972 and 1976 respectively. He retired as a Professor of Electronics and Communication Engineering, Anna University in 2005. Since then, he is a senior Professor in St.Joseph Engineering college, Chennai, India. He has produced $40 \mathrm{PhD}$ 's and he is the author of well over 500 publications in reputed Journals and Conference Proceedings. He is a Life Fellow/Life member in about two dozen professional societies. He is the recipient of about a dozen

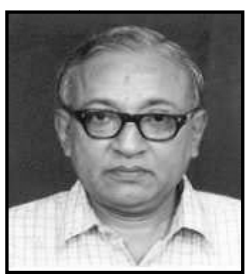
awards. His areas of interest include Logic design, graph algorithms, networks, image processing and robotics. 